\title{
PROCEDIMENTOS DE TRANSFORMAÇÃO TÊXTIL EM TECIDO DE MALHA ${ }^{1}$.
}

\author{
Maria Izabel Costa ${ }^{2}$, Ingrid Lagemann Isoppo ${ }^{3}$, Bárbara Jung da Rosa ${ }^{4}$, Melina Makowieck ${ }^{4}$, \\ Geise Fabiane Nazario ${ }^{5}$, Tadeu Damo ${ }^{6}$, Gabriele Louise Ribeiro da Silva ${ }^{6}$
}

Palavras-chave: moda - design têxtil - tecido de malha - transformação têxtil

Resumo: Este texto apresenta resultados parciais da pesquisa que objetiva a criação de novos produtos têxteis, a partir da transformação da estrutura e do design de superfície do tecido de malha circular, fornecido pela empresa Sun Camisetas Ltda (SC). Aplica Procedimentos de Transformação Têxtil Estrutural, Construtivo, Colorístico e Combinado bem como a Sinética como técnica facilitadora do processo criativo.

A pesquisa que envolve a transformação têxtil tem sido valorizada no âmbito da moda, pois permite agregar valor técnico/estético diferenciado a um produto industrializado, proporcionando maior variedade estilística ao profissional de moda e maior otimização da matéria prima ao empresário. Pesquisar a transformação da malha circular vem completar uma série de pesquisas da UDESC, na área têxtil, como a transformação do nãotecido (COSTA,2003), pesquisa desenvolvida em parceria com a empresa Freudenberg (SP); transformação do tecido plano (COSTA, 2005), desenvolvida na disciplina Desenho Têxtil II; e em malha retilínea (BERVIAN, 2005), pesquisa desenvolvida em Trabalho de Conclusão de Curso com a Empressa Téssere Malharia(RS). Contudo, o emprego dos Procedimentos de Transformação Têxtil ainda não foram empregados e testados com o tecido de malha circular - ponto Jersey . Acredita-se que, pode-se gerar uma série de bandeiras (amostras de tecidos) com diferencial agregado em termos de estrutura e estética de superfície. Neste escopo, coube a seguinte questão de pesquisa: como propor novas estruturas têxteis a partir da transformação do tecido de malharia circular com vistas à utilização intencional para o produto de moda? No momento, já se concluiu a etapa de desenvolvimento de bandeiras têxteis em laboratório experimental, que será o foco deste artigo, e parte-se para a segunda etapa que consiste na aplicação destas amostras em coleção de moda visando o estudo da viabilidade funcional dos tecidos criados.

Conforme, Ribeiro (1984, p. 63) "Tecido é um produto manufaturado, em forma de lâmina flexível, resultante do entrelaçamento, de forma ordenada ou desordenada, de fios ou fibras têxteis entre si". Pela forma como os fio ou fibras são trabalhados para a formação de uma estrutura têxtil, tem-se diferentes tipos de tecidos. Quanto a sua formação, o autor classifica os têxteis em Tecidos Comuns (tecidos planos, formados pelo entrelaçamento de fios de urdume e trama em ângulo reto); Tecidos de Malha (constituídos pelo entrelaçamento de fios em forma de

\footnotetext{
${ }^{1}$ Projeto de Pesquisa CEART/UDESC.

${ }^{2}$ Orientadora, Professora do Departamento de Moda - Centro de Artes - Av. Madre Benvenuta, 2007 - CEP 88035-001-

Florianópolis - SC

${ }^{3}$ Acadêmica do Curso de Bacharelado em Moda - CEART/UDESC, bolsista PROBIC 2007/1

${ }^{4}$ Acadêmicas do Curso de Bacharelado em Moda - CEART/UDESC, bolsistas PROBIC 2006/1

${ }^{4}$ Acadêmicas do Curso de Bacharelado em Moda - CEART/UDESC, bolsistas PROBIC 2006/1

${ }^{5}$ Acadêmica do Curso de Bacharelado em Moda - CEART/UDESC, bolsista PIVIC 2007/1

${ }^{6}$ Acadêmicos do Curso de Bacharelado em Moda - CEART/UDESC, bolsistas PIVIC 2006/2

${ }^{6}$ Acadêmicos do Curso de Bacharelado em Moda - CEART/UDESC, bolsistas PIVIC 2006/2

DAPesquisa, Florianópolis, v.2, n.4, p. 445-450, 2007.
} 
laçadas); Tecidos de Laçada (o mesmo que tecido de renda, obtido por laçadas completas em forma de nós); Tecidos Nãotecidos (desenvolvidos por tecnologia especifica que resulta na compactação de fibras e/ou fios sem que estes estejam tramados), e Tecidos Especiais (formados pela junção de mais que um tipo de estrutura acima descritas ou resultantes da adição de polímeros em forma de filmes). O tecido deve apresentar, segundo Araújo (1987, p.919), o comprimento e a largura significativamente superiores à espessura, sendo a sua resistência mecânica suficiente para lhe dar coesão.

Considerando-se a matéria prima e objeto de transformação têxtil deste estudo, abordar-se-á apenas as propriedades do Tecido de Malha.

Independentemente de sua produção (artesanal ou industrial), tecidos de malha podem ser definidos como os "resultantes da formação de laços que se interpenetram e se apóiam lateral e verticalmente, provenientes de um ou mais fios" (RIBEIRO, 1984, p. 65).

Os tecidos de malha podem ser produzidos por dois métodos básicos: urdume e trama. Para a produção de malha por urdimento, tem-se o processo que utiliza o método de entrelaçamento de malhas no sentido do urdume (sentido vertical), empregando numerosos fios que se entrelaçam lateralmente e podem alimentar uma ou mais agulhas. Caracterizam-se pela boa estabilidade dimensional e, devido a isso, não se deformam facilmente. Também, possuem menor elasticidade que os tecidos de malha por trama e são indesmalháveis.

Os tecidos de malha por trama são estruturas resultantes do entrelaçamento de um único grupo de fios entre si através de laçadas no sentido da largura do tecido,ou seja, na direção da trama - sentido horizontal. Todas as agulhas são alimentadas por um mesmo fio ou grupo de fios e as malhas são formadas sucessivamente. A malha por trama pode ser circular (produzida na forma de um tubo) ou retilínea (consiste numa malha aberta, geralmente com largura variável entre $1,40 \mathrm{~cm}$ e $1,60 \mathrm{~cm}$, fabricada em máquinas planas). Estes artigos de malha por trama caracterizam-se pela pouca estabilidade dimensional, o que facilita a sua deformação, além de apresentarem elasticidade nos dois sentidos. São também tecidos desmalháveis. As estruturas fundamentais da malharia por trama, segundo Andrade Filho e Santos (1987), resumem-se nos pontos jersey (meia-malha), rib (canelado) e ponto reverso (links). A malha jersey "é formada pela repetição da laçada normal na direção das colunas e na direção das fileiras [cursos]" (ARAÚJO, 1984, p. 483). Sua principal característica refere-se ao entrelaçamento de pontos na mesma direção, no lado direito da malha, enquanto, no avesso, as laçadas aparecem de forma semi-circular. A malha jersey "apresenta um certo desequilíbrio pelo fato de o lado direito apresentar laçadas, ao passo que o lado avesso técnico só apresenta listras horizontais" (SMITH, 1989, p. 16). Por esse motivo, a malha jersey possui uma única face, ao contrário das malhas rib e de ponto reverso, ambas com duas e com a mesma aparência tanto do lado direito quanto do avesso, ainda que suas estruturas sejam completamente diferentes. Outra característica atribui-se ao fato da malha jersey desmalhar livremente em qualquer um dos lados.

O tecido da empresa Sun Caminestas Ltda, utilizado nesta pesquisa, é uma malha de trama, de ponto Jersey (meia-malha) e, portanto, para a transformação têxtil, foram observadas estas características acima apontadas.

Por transformação têxtil, entende-se as mudanças artesanais ou industriais, ocasionadas na estrutura do substrato têxtil (tecido), ou em seu relevo, ou na coloração ou combinação destas.

A designação de procedimentos Estrutural, Construtivo, Colorístico e Combinado surgiu a partir de pesquisa desenvolvida com o substrato têxtil nãotecido (COSTA,2003). Hoje, estes procedimentos são adotados na disciplina de Desenho Têxtil do Curso de Bacharelado em Moda - UDESC e tem propiciado a organização da prática experimental na transformação têxtil artesanal de diversos substratos têxteis.

O Procedimento Estrutural caracteriza-se pela mudança da estrutura do substrato têxtil. No caso da malha, deve-se atuar no sentido de descaracterizá-la enquanto estrutura em forma de laçada. Sendo assim, as intervenções como recorte em tiras para posterior emprego de técnicas como a tecelagem, malimo, macramé, fuxico, entre outras, são válidas.

DAPesquisa, Florianópolis, v.2, n.4, p. 445-450, 2007. 
Procedimento Construtivo é aquele que utiliza a sobreposição de tecidos uns sobre os outros, ou modifica-se a superfície do substrato a ser transformado visando dar ênfase ao relevo, textura, como também, reforço dos substratos de baixa gramatura. Emprega-se técnicas de sobreposições/apliques, "esculpimentos", bordados, bem como matelassês e tecidos dublados, entre outras.

O Procedimento Colorístico caracteriza-se pela transformação da matéria-prima têxtil pela agregação de cor. Neste procedimento estão agrupadas as técnicas que objetivam colorir os tecidos, através de tingimento (coloração total do tecido) ou aplicar desenhos através de estamparia (coloração parcial). Várias são as técnicas de estamparia e de tingimento (tie-dye, batik, descoloramento, pintura a mão, carimbo, serigrafia, sublimação, estamparia digital, etc.).

O Procedimento Combinado, caracteriza-se pela utilização de mais que uma das técnicas descritas anteriormente. Se os procedimentos anteriores já possibilitam o desenvolvimento de uma grande quantidade de bandeiras, com este (Procedimento Combinado), as possibilidades criativas se ampliam ao máximo. Para organizar o processo criativo e melhor visualizar as possibilidades de utilização deste procedimento, empregou-se o quadro "Formação do Procedimento Combinado" (COSTA, 2003), que consiste no cruzamento dos Procedimentos de Transformação Têxteis entre si, com suas respectivas técnicas de desenvolvimento dos tecidos.

O cruzamento pode dar-se também entre técnicas do mesmo procedimento.

Além da fundamentação teórica que envolve o produto e processo da malharia e os procedimentos de transformação têxtil , o estudo a respeito da Sinética também foi considerado para embasar a pesquisa, servindo de instrumento facilitador do processo criativo.

Para Virgolim (1994), Sinética é uma palavra de origem grega, que significa a associação de elementos diferentes e aparentemente irrelevantes. Segundo Baxter (1998, p.69), a palavra sinética é derivada do grego e significa juntar elementos diferentes, aparentemente não relacionados entre si. A técnica tem como objetivos: permitir que o indivíduo perceba a realidade de forma não corriqueira, fazendo com que um grupo de pessoas faça emergir, do nível inconsciente, várias idéias visando à solução do problema proposto; aumentar a consciência e os mecanismos que podem ser utilizados para chegar soluções novas de um problema; obter respostas de qualidade e não a quantidade delas.

A sinética reconhece dois tipos de mecanismos mentais: transformar o estranho em familiar e transformar o familiar em estranho. Este segundo recorre a quatro tipos de analogias: analogia pessoal; direta; simbólica; fantasiosa (ALENCAR,1995, p.22). Destas, utilizou-se, a analogia Direta que consiste na comparação direta de fotos, elementos vivos, conhecimentos ou tecnologias paralelas. Esses paralelos são buscados em situações da natureza e, por isso, muito empregados na biônica. Para se fazer a analogia direta fez-se a seguinte pergunta: De que forma o reino vegetal utiliza-se para reforçarem as suas estruturas? De que forma se encontra na natureza exemplos ou modelos de beleza para dar-se como característica a um Tecido?

Através da sinética direta e, utilizando-se sementes brasileiras como referência para a inspiração do desenho têxtil, empregou-se diversas formas de análise (diacrônica, sincrônica, estrutural, morfológica) utilizadas por Aquistapasse (2001). A Análise Diacrônica consistiu em pesquisa bibliográfica para retiradas de imagens e dados. Na Análise Sincrônica, realizou-se uma pesquisa bibliográfica na intenção de verificar um universo mais amplo onde houvesse a presença da semente, em outros campos, como na história da arte. A Análise Estrutural consistiu em realizar a escolha da semente que seria a referência da criação, bem como as partes da planta, fruto e flores. A Análise Morfológica, permitiu que se retirassem a cor (tabela de cores com as tonalidades), a forma (uma interpretação mais geométrica do desenho e outra com traços mais gestuais) e a textura das sementes.

Cabe ressaltar também que o estudo de simetrias contribuiu para desenvolver uma série de outros padrões a partir de uma figura estabelecida. Neste sentido, quanto a simetria e ao jogo resultante das análises combinatórias entre elas, (GOMES,1994 apud AQUISTAPASSE, 2001), em suas considerações sobre composição de "elementos, motivos e padrões" gráficos, nos diz que estes

DAPesquisa, Florianópolis, v.2, n.4, p. 445-450, 2007. 
podem ser iniciados seguindo algumas leis de simetria, a saber: isografia, homeografia, singenografia, catagrafia e heterografia.

Estes estudos teóricos contribuíram com o processo de transformação do tecido de malha que foi concretizado, metodologicamente, pelas seguintes etapas:

1- Estudo das características e propriedades da matéria-prima a ser transformada. Nesta etapa, passou-se a conhecer o substrato têxtil analisando e identificando, por meio de dados fornecidos pela empresa, a composição, a gramatura, tipo de malha, sua forma de apresentação para comercialização, campo de aplicação original, suas características técnicas e estéticas;

2- Experimentação dos procedimentos de transformação têxtil: Estrutural (elaboração através de estruturas), Construtivo (elaboração através de sobreposições de materiais e/ou apliques), Colorístico(elaboração através de tingimento/estamparia )e Combinado ( empregando-se mais do que uma das técnicas dos procedimentos anteriores);

3- Testes e adequação. Nesta etapa, as transformações foram testadas através de lavagens em máquina doméstica onde verificou-se a resistência dos procedimentos aplicados.

4 Elaboração e Preenchimento de Fichas de Registro Têxtil - memorial descritivo e fotográfico do produto. Além das características técnicas, os apelos estéticos, dirigidos pela percepção, visão e tato - mesmo sendo mais subjetivos e culturais, foram analisados e registrados, procurando-se como critério, a própria comparação entre a matéria prima original estudada. Assim, a cor, o desenho, o brilho, relevo e textura são os principais fatores visuais aos quais se juntam os fatores táteis. Estes, traduzidos em sensações de maciez e aspereza, de quente e de frio; de dureza e moleza, de flexibilidade e rigidez, de elasticidade; de volume (espessura), de peso e outros, compõem o atributo "toque".

5- Aplicação em produtos de moda (esta última fase ainda está em estudo).

Como resultado, neste primeiro ano (Jul 2006-Jul 2007) foram pesquisadas as características técnicas/estéticas do tecido de meia malha e produzidas 119 bandeiras têxteis de $0,50 \mathrm{~m}$ de comprimento X 0,40m de largura, sendo que:

21 são do Procedimento Estrutural;

22 " " Construtivo;

36 " " " Colorístico;

40 " " Combinado.

Todas as bandeiras criadas já possuem suas Fichas de Registro Têxtil elaboradas constando todas as informações referente à matéria prima, composição ( \%fibra têxtil utilizada); tamanho amostra têxtil; descrição procedimento/ técnica de elaboração do produto; registro fotográfico, entre outros dados.

Foram realizados diversos estudos para estamparia corrida e localizada empregando-se a técnica "Sinética Direta" com o tema sementes brasileiras como fonte de inspiração para o desenho têxtil. A metodologia de transformação têxtil desta pesquisa foi adotada como conteúdo em uma unidade da Disciplina de Desenho Têxtil II, da $7^{\text {a }}$ fase do Curso de Bacharelado em Moda, e tem sido positiva ao ensino, ois emprega o trabalho reflexivo/prático envolvendo os alunos à pesquisa. maioria das bandeiras da pesquisa (95\%) já foram catalogadas e encontram-se na Teciteca do Ceart.

Concluindo, pode-se dizer que a pesquisa tem mostrado que é possível realizar todos os procedimentos de transformação têxtil no tecido de malha circular. Desta forma, um tecido básico, utilizado geralmente para a confecção de camisetas, é passível de transformações tanto na sua estrutura quanto em sua superfície. $\mathrm{O}$ valor estético agregado pode ser utilizado em outras peças do vestuário, proporcionando maior variedade estilística ao produto.

Observa-se uma maior quantidade de bandeiras criadas a partir do procedimento Combinado que emprega mais que uma técnica para a transformação têxtil, pois vem possibilitar uma maior aproximação do tecido criado com o tema proposto - sementes brasileiras.

DAPesquisa, Florianópolis, v.2, n.4, p. 445-450, 2007. 
As características próprias do ponto jersey - malha por trama- de apresentar pouca estabilidade dimensional, foi utilizada como recurso positivo, principalmente na construção de rolotês. Contudo, a característica "desmalhável" não foi muito utilizada, pois a malha muito fina de algodão não desmalha tão facilmente quanto um tecido de tricô. No Procedimento Estrutural, a técnica de tecelagem e malimo foram as mais utilizadas, a partir do corte transversal da malha em tiras. Através do Procedimento Construtivo, pode-se desenvolver novos produtos que atenderão principalmente a meia estação e o inverno por apresentarem sobreposições de materiais elevando a gramatura têxtil. O desenvolvimento de bandeiras com o Procedimento Colorístico torna-se acessível na maioria das técnicas de estamparia e tingimento por ter a meia-malha estrutura de superfície lisa e, em geral, ter composição $100 \%$ algodão que é uma fibra que aceita facilmente corantes e pigmentos. A estamparia digital não foi experimentada.

A utilização da técnica de criatividade sinética foi produtiva na resolução de problemas que dizem respeito mais à criação estética que a problemas de resistência têxtil ou de deformidade da malha. Este fato deveu-se a um maior interesse da equipe de pesquisa nos aspectos estéticos. A escolha de sementes não tinha como objetivo o estudo da função e resistência destas na natureza para servir de modelo para a resolução de problemas técnicos/funcionais do tecido.

A participação dos alunos da Disciplina de Desenho Têxtil em parte específica desta pesquisa tem mostrado o lado positivo da integração ensino-pesquisa. Da mesma forma, o interesse da empresa e sua atitude de colaboração, sem interferência na parte criativa dos designers (equipe de pesquisa) tem facilitado o processo. Contudo, a resposta da viabilidade da pesquisa para a área de confecção, ainda está em andamento e, em breve, virá com o término da última etapa, onde as bandeiras serão transformadas em peças do vestuário na concretização de uma coleção de moda.

1 Projeto de Pesquisa CEART/UDESC.

2 Orientadora, Professora do Departamento de Moda - Centro de Artes - Av. Madre Benvenuta, 2007 - CEP 88035-001- Florianópolis - SC.

3 Acadêmica do Curso de Bacharelado em Moda - CEART/UDESC, bolsista PROBIC 2007/1

4 Acadêmicas do Curso de Bacharelado em Moda - CEART/UDESC, bolsistas PROBIC 2006/1

5 Acadêmica do Curso de Bacharelado em Moda - CEART/UDESC, bolsista PIVIC 2007/1

6 Acadêmicos do Curso de Bacharelado em Moda - CEART/UDESC, bolsistas PIVIC 2006/2

Referências

ALENCAR, EUNICE M.L. SORIANO DE. Criatividade. Brasília: Editora Universidade de Brasília, 1995.

AQUISTAPASSE, LUSA ROSÂNGELA LOPES. Cultura Material: a estamparia têxtil como

fator de inovação no comércio de tecidos de lã. Dissertação de mestrado. Programa Pós-

Graduação em Engenharia de Produção. PPGEP - UFSM, 2001

ANDRADE FILHO, JOSÉ FERREIRA DE \& SANTOS, LAÉRCIO FRAZÃO DOS.

Introdução a Tecnologia Têxtil. Rio de Janeiro: SENAI/CETIQT, 1987.

ARAÜJO, MARIO DE \& CASTRO, E.M. de Melo. Manual de Engenharia Têxtil. Lisboa:

Fundação Calouste Gulbenkian, 1987.

BAXTER, M. Projeto de produto. São Paulo: Editora Edgard Blucher Ltda., 1998.

BERVIAN, BRUNA. Malharia Retilínea: um universo de possibilidades para a empresa Téssere

Malharia Retilínea. Trabalho de Conclusão de Curso. UDESC/SC, Florianópolis, 2005.

COSTA, MARIA IZABEL. Transformação do Nãotecido: uma abordagem do design têxtil

em produtos de moda. Dissertação de Mestrado- Programa de Pós-Graduação em Engenharia de Produção . UFSC/SC, Florianópolis, 2003.

DAPesquisa, Florianópolis, v.2, n.4, p. 445-450, 2007. 
,. Chita Bacana: Aplicação dos Procedimentos de Transformação Têxtil em Tecido Plano. In: Anais $3^{\circ}$ CONGRESSO INTERNACIONAL EM PESQUISA E DESIGN, 2005, Rio de Janeiro/RJ, 2005.

RIBEIRO, LUIZ GONZAGA. Introdução à Tecnologia Têxtil. Rio de Janeiro: SENAI/ CETIQT, 1984.

SMITH, GARY W. Controle de qualidade na indústria de malhas. Rio de Janeiro: SENAI/ CETIQT, 1989

VIRGOLIN, A. M.R; Alencar, E.M.L.S. Criatividade: expressão e desenvolvimento. Petrópolis: Vozes, 1994.

DAPesquisa, Florianópolis, v.2, n.4, p. 445-450, 2007. 